\title{
COMBINATION OF ORIGANUM VULGARE L. ESSENTIAL OIL AND LACTIC ACID TO INHIBIT STAPHYLOCOCCUS AUREUS IN MEAT BROTH AND MEAT MODEL
}

\author{
Jefferson C. de Barros, Maria Lúcia da Conceição, Nelson Justino Gomes Neto, Ana Caroliny Vieira da Costa, Evandro \\ Leite de Souza*
}

Laboratório de Microbiologia de Alimentos, Departamento de Nutrição, Centro de Ciências da Saúde, Universidade Federal da Paraíba, João Pessoa, PB, Brasil.

Submitted: September 24, 2009; Returned to authors for corrections: May 18, 2010; Approved: June 07, 2012.

\begin{abstract}
This study assessed the occurrence of an enhancing inhibitory effect of the combined application of Origanum vulgare L. essential oil and lactic acid against Staphylococcus aureus by the determination of Fractional Inhibitory Concentration (FIC) index and cell viability in meat broth and meat model. Minimum Inhibitory Concentration (MIC) and Minimum Bactericidal Concentration (MBC) of the oil was 0.6 and $1.25 \mu \mathrm{L} . \mathrm{mL}^{-1}$, respectively. Lactic acid showed MIC and MBC of 2.5 and $5 \mu \mathrm{L} . \mathrm{mL}^{-1}$, respectively. FIC indices of the combined application of the oil and lactic acid were 0.5 showing a synergic interaction. The essential oil and lactic acid showed similar ( $>0.05)$ anti-S. aureus effect in meat broth over $96 \mathrm{~h}$ of exposure. Treatment with essential oil or lactic acid presented a smaller anti-staphylococcal effect in meat in comparison to meat broth. No significant difference $(\mathrm{p}>0.05)$ was found for the microbial counts in meat treated with each antimicrobial alone or in mixture. These results could arise as an interesting approach for the improvement of food preservation using more natural procedures, considering the current demand of consumer and sensory quality of foods.
\end{abstract}

Key words: essential oil, organic acid, hurdle technology, combined effect.

\section{INTRODUCTION}

Staphylococcus aureus is a pathogen bacterium commonly associated with serious outbreaks of food poisoning attributed to contaminated meat products $(8,23)$. Staphylococcal enterotoxins form a family of major serological types of heatstable enterotoxins that cause vomiting and diarrhoea when ingested and are responsible for staphylococcal food poisoning
(26). Since staphylococcal foodborne intoxication is established as one of the most common bacterial food-borne diseases causing problems in the food sector in many countries, strategies to control $S$. aureus in foods are of particular interest.

Food conservation is based on a search for foods with a high nutritional quality and microbial stability and it has been reached by the use of various physical and/or chemical procedures (9). However, there is a current demand from 
consumers for new methods of reducing or eliminating foodborne pathogens, possibly in combination with existing methods. Consumers are requesting additive-free, fresher, more natural tasting foods and with a smaller impact on the environment, while maintaining the microbiological safety $(7$, 17, 29). One such possibility is the use of essential oils as antimicrobial additives $(18,31)$. It has long been recognized that essential oils have antimicrobial properties but the recent enhancement of interest in "green" consumerism has lead to a renewed scientific interest in these substances (30).

It is reported that the application of natural compounds for controlling food-related pathogenic microorganisms demands the evaluation of efficacy with food model media and food products since the food components may reduce their antimicrobial effect (14). Others researchers have purposed that results obtained in liquid and/or solid food model media may be more useful prior to further application in/on food matrices, rather than those obtained in laboratorial media. Smith-Palmer et al. (28) and Gutierrez et al. (16) stated that these food-based models would also better reflect the nutrient availability and composition of foods, optimizing the final application of these compounds.

The main drawback of using essential oils as antimicrobial in foods is the high concentration needed to inhibit spoilage and pathogen bacteria in food matrices which often exceeds the flavor threshold acceptable to consumers. Combination of essential oils with existing physical or chemical treatments (Hurdle Technology concept) could rise as effective approach for reinforcing their natural antimicrobial effects. The addition of small amounts of other natural preservatives may be a way to provide the balance between sensory acceptability and antimicrobial efficacy (10).

The use of essential oils with other food ingredients, such as sodium chloride, sugar and organic acid might provide an enhancing effect for control the microbial growth in foods (11, 20). Organic acids are either naturally present as constituents of the food or added to the products through the food formulation.
Lactic acid lacks in acute and chronic toxicity, which has lead to its widespread employment as a classical food preservative and decontamination agent (13).

Among many plants scientifically studied regarding their antimicrobial properties, Origanum vulgare L. (oregano), Lamiaceae, has showed prominent results $(27,29)$. O. vulgare essential oil presented interesting results in inhibiting the growth of bacteria and synthesis of microbial metabolites, including the pathogen Staphylococcus aureus (2, 3, 22, 30). Although, some researchers have found anti-Staphylococcal activity in $O$. vulgare essential oil, there is a lack of information about its antimicrobial effect when applied in combination with other antimicrobial compounds.

This study was undertaken to investigate the occurrence of an enhancing anti-S. aureus effect on the basis of FIC index and cell viability assay. Potential synergy between $O$. vulgare essential oil and the classical and widely applied food preservative lactic acid in meat based broth and in a meat model was investigated. To our knowledge, the effect of the combined application of $O$. vulgare essential oil and an organic acid at sub-inhibitory concentrations against the food-related pathogen $S$. aureus has not been reported to date.

\section{MATERIALS AND METHODS}

\section{Antimicrobial agents}

Lactic acid (85 - 90\%) was obtained from Vetec Química Fina Ltda. (Rio de Janeiro, Brazil). Stock solutions of the acid were made in sterile distilled water.

The essential oil from O. vulgare L. (Batch 209) extracted by hydrodistillation was supplied by Ferquima Ind. e Com. Ltda. (Vargem Grande Paulista, São Paulo, Brazil). Stock solutions of the essential oil were prepared in distilled water added of bacteriological agar $\left(0.15 \mathrm{~g} .100 \mathrm{~mL}^{-1}\right)$ as stabilizing agent (5). According to Barros et al. (2) the essential oil assayed here possesses carvacrol (57.71\%), p-cymene (10.91\%), $\gamma$-terpinene $(7.18 \%)$ and terpinen-4-ol (6.68\%) as its 
major compounds.

Lactic acid and essential oil were assayed at concentrations of $80,40,20,10,5,0.5,0.25,0.125,0.06,0.03$ and $0.0015 \mu \mathrm{L} \cdot \mathrm{mL}^{-1}$.

\section{Bacterial strains}

S. aureus QCD, S. aureus QCE and S. aureus QCF obtained from the Microorganism Collection, Laboratory of Food Microbiology, Health Sciences Center, Federal University of Paraíba, João Pessoa, Brazil were used as test microorganisms. These strains were isolated from different unripened cheese samples by the standard procedures $(1,4)$. Stock cultures were kept on Nutrient Agar - NA (Sigma, France) slants under refrigeration.

Inocula used in antimicrobial assays were obtained from overnight cultures grown on NA slants at $37^{\circ} \mathrm{C}$. A loopfull of the culture was diluted in sterile saline solution $\left(0.85 \mathrm{~g} .100 \mathrm{~mL}^{-}\right.$ $\left.{ }^{1}\right)$ to have a final concentration of approximately $10^{8}$ colony forming unity per $\mathrm{mL}$ (cfu.mL $\mathrm{mL}^{-1}$ ) adjusted according to the turbidity of $0.5 \mathrm{McF}$ arland standard.

\section{Preparation of meat broth}

Bovine meat steaks were trimmed for all external fat and cut in pieces of uniform sizes $(3 \times 3 \times 3 \mathrm{~cm})$. Meat pieces were boiled in distilled water during $20 \mathrm{~min}$ at $90{ }^{\circ} \mathrm{C}$. About $500 \mathrm{~mL}$ of meat broth were obtained and vacuum filtered using Whatman $\mathrm{n}^{\circ} 1$. The filtrate was sterilized using autoclave for 15 $\min (1.21 \mathrm{~atm})$. After that, the broth was stored at $-20^{\circ} \mathrm{C}$ in aliquots of $50 \mathrm{~mL}$. When required one aliquot was thawed under refrigeration $\left(7^{\circ} \mathrm{C}, \pm 1^{\circ} \mathrm{C}\right)$ and used for the experimental analysis.

\section{Determination of the Minimum Inhibitory Concentration} (MIC) and Minimum Bactericidal Concentration (MBC)

MIC and MBC values of the essential oil and lactic acid were determined using the macrodilution in broth procedure. 5 $\mathrm{mL}$ of double strength Nutrient Broth-NB (Sigma, France) was inoculated with $1 \mathrm{~mL}$ of the bacterial inocula (approximately
$10^{7}$ cfu. $\mathrm{mL}^{-1}$ ). After that, $4 \mathrm{~mL}$ of the essential oil or lactic acid solution at appropriate concentration was added, followed by shaking for $30 \mathrm{~s}$, and then incubated for $24 \mathrm{~h}$ at $37^{\circ} \mathrm{C}$ without shaking. MIC was defined as the lowest concentration of the assayed antimicrobial agent required to completely prevent visible bacterial growth in NB. An aliquot $(100 \mu \mathrm{L})$ of the tubes with no visible bacterial growth was subcultured on sterile NA Petri dishes at $37^{\circ} \mathrm{C}$ for $48 \mathrm{~h}$ to determine if the inhibition was reversible or permanent. MBC was defined as the lowest concentration which no growth was noted on NA. Control flasks without essential oil or lactic acid were tested in the same way (12).

\section{Synergy assays}

The study of synergy of $O$. vulgare essential oil and lactic acid was carried out by determining Fractional Inhibitory Concentration (FIC). For this, was used the macrodilution procedure using NB as previously described. FIC was calculated as follow: FIC: MIC of the oil in combination of lactic acid / MIC of the oil alone. The essential oil and lactic acid were combined at MIC + MIC; MIC + 1/2 MIC; MIC + 1/4 $\mathrm{MIC} ; 1 / 2 \mathrm{MIC}+1 / 2 \mathrm{MIC} ; 1 / 4 \mathrm{MIC}+1 / 4 \mathrm{MIC}$; and $1 / 2 \mathrm{MIC}+1 / 4$ MIC. Synergy was FIC $\leq 0.5$; indifference was FIC $>0.5$ to 4; and antagonism was FIC $>4$ (14).

\section{Cell viability assay}

The effect of the antimicrobials alone and in combination on the cell viability of $S$. aureus QCE along $96 \mathrm{~h}$ was evaluated by the viable cell count procedure. For this, $5 \mathrm{~mL}$ of meat broth was inoculated with $1 \mathrm{~mL}$ of the bacterial inocula (approximately $10^{7}$ cfu. $\mathrm{mL}^{-1}$ ) and $5 \mathrm{~mL}$ of the antimicrobial (alone or in combination) solution at appropriated concentration were added to the system, gently shaken for $30 \mathrm{~s}$, and then incubated at $7^{\circ} \mathrm{C}\left( \pm 1^{\circ} \mathrm{C}\right)$. At different time intervals $(0,24,48,72$ and $96 \mathrm{~h}), 1 \mathrm{~mL}$ of the suspension was serially diluted $\left(10^{-1}-10^{-5}\right)$ in sterile peptone water $\left(0.1 \mathrm{~g} .100 \mathrm{~mL}^{-1}\right)$ and inoculated on NA Petri dishes for $24 \mathrm{~h}$ at $37^{\circ} \mathrm{C}$. Control flasks with no antimicrobial were tested in the same way. The 
mean number of colonies was counted and compared with that found in the control assay. The results were expressed in log of cfu. $\mathrm{mL}^{-1}$.

\section{Meat model}

Bovine meat steaks were trimmed for all external fat and cut in pieces of uniform sizes $(3 \times 3 \times 3 \mathrm{~cm})$. The meat pieces were put in glass flasks and sterilized using autoclave $\left(121^{\circ} \mathrm{C}\right.$ for $15 \mathrm{~min}, 1.21 \mathrm{~atm})$. After that, meat pieces were inoculated with a staphylococcal suspension according to the following procedure: the pieces were individually submerged in $50 \mathrm{~mL}$ of the bacterial inoculum ( $S$. aureus QCE, approximately $10^{7}$ cfu. $\mathrm{mL}^{-1}$ ) prepared in sterile saline solution, rotated with sterile glass stick for $1 \mathrm{~min}$ to ensure even inoculation, air dried for 30 min in a bio-safety cabinet before washing with the antimicrobials. The pieces were randomly divided into four groups and immersed for $30 \mathrm{~s}(1: 4 \mathrm{w} / \mathrm{v})$ as follow: (1) control dipped in sterile distilled water; (2) dipped in the essential oil MIC solution; (3) dipped in lactic acid MIC solution; and (4) dipped in essential oil (MIC x 1/4) + lactic acid (MIC x $1 / 4$ ) solution. The pieces were put in sterile sealed sterile polypropylene cups and stored under refrigeration $\left(7^{\circ} \mathrm{C}, \pm 1^{\circ} \mathrm{C}\right)$. At $0,24,48,72$ and $96 \mathrm{~h}$ of storage the meat samples were submitted to count of $S$. aureus according to procedure described for Vanderzant and Splittstoesser (32). The results were described in log of cfu per gram of meat (log cfu.g meat $1)$.

All antimicrobial assays were carried out in triplicate and the results are expressed as average of the three parallel assays.

\section{Statistical analysis}

Statistical analysis was performed to determine significant differences $(\mathrm{p}<0.05)$ by one-way ANOVA followed for Tukey test in the bacteria kill time assays. For this the Sigma stat 2.03 computer program was used.

\section{RESULTS AND DISCUSSION}

All test strains were sensitive to $O$. vulgare essential oil and lactic acid, although the oil presented four-fold smaller $\mathrm{MIC}$ and $\mathrm{MBC}$ values in comparison to the acid. MIC value of O. vulgare essential oil was $0.6 \mu \mathrm{L} \cdot \mathrm{mL}^{-1}$ for all strains, while MBC was $1.25 \mu \mathrm{L} . \mathrm{mL}^{-1}$. Lactic acid showed MIC and MBC of 2.5 and $5 \mu \mathrm{L} . \mathrm{mL}^{-1}$, respectively.

FIC indices of the combined application of $O$. vulgare essential oil and lactic acid were 0.5 for all $S$. aureus strains revealing a synergic activity of the assayed antimicrobials. Test strains presented capability to grow at sub-inhibitory concentrations ( $1 / 2$ MIC and $1 / 4$ MIC) of both antimicrobials when applied alone (Table 1).

Table 1. FIC indexes of the combined action of $O$. vulgare L. essential oil and lactic acid to $S$. aureus strains.

\begin{tabular}{lccccccc}
\hline Strains & FIC & \multicolumn{2}{c}{ O. vulgare essential oil } & & & \multicolumn{2}{c}{ Lactic acid } \\
\cline { 3 - 4 } & & MIC x 1/2 & MIC x 1/4 & & MIC x 1/2 & MIC x 1/4 \\
\hline S. aureus QCD & 0.5 & + & + & + & + & + \\
S. aureus QCE & 0.5 & + & + & & + & + \\
S. aureus QCF & 0.5 & + & & & + & + \\
\hline
\end{tabular}

$\overline{(+) \text { : capability of the strain to grow in nutrient broth added of the essential oil or lactic acid at each assayed sub-inhibitory concentrations }}$

Synergy is observed when the effect of the combined compounds is greater than the sum of the individual effects (6). Gutierrez et al. (15) found no synergy by FIC index when oregano essential oil was applied in combination to thyme or marjoram essential oil toward P. aeruginosa, B. cereus, E. coli and L. monocytogenes. According to the authors as the assayed 
essential oils possess similar composition their combination may exhibit addition rather than a synergistic effect. Nazer et al. (21) found that thymol in combination with other aromatic compounds, lead to improved inhibition, but no real synergistic effect was demonstrated toward Salmonella.

When cell viability assay is combined with FIC assay, much more kinetic information can be generated giving a dynamic picture of the antimicrobial interactions (14). Results of the effect of $O$. vulgare essential oil (MIC), lactic acid (MIC) and O. vulgare essential oil ( $1 / 4 \mathrm{MIC})$ in combination with lactic acid $(1 / 4 \mathrm{MIC})$ in meat broth at $7^{\circ} \mathrm{C}$ on the cell viability of $S$. aureus QCE are given in Figure 1. The temperature of $7^{\circ} \mathrm{C}$ was chosen regarding the use of a more realistic temperature in respect of the most common conservation systems applied to meat products. In meat broth the essential oil provided a prominent drop in the bacterial inoculum after $24 \mathrm{~h}$, followed for a steady and smaller decrease in the remainder evaluated times. Lactic acid caused a sharply drop in bacterial inoculum after $24 \mathrm{~h}$, however a slight increase in the bacterial count occurred in the reminder intervals. Along the evaluated intervals the count found for the media added of essential oil and lactic acid at sub-inhibitory concentrations were significantly lower $(\mathrm{p}<0.05)$ than those found for the control assay. No significant difference $(p<0.05)$ was noted between the microbial counts found for the broth added of lactic acid at MIC and added of both antimicrobials at subinhibitory concentrations.

Results of the effect of O. vulgare essential oil (MIC), lactic acid (MIC) and $O$. vulgare essential oil ( $1 / 4 \mathrm{MIC})$ in combination with lactic acid ( $1 / 4 \mathrm{MIC})$ on the cell viability of $S$. aureus $\mathrm{QCE}$ in meat model at $7^{\circ} \mathrm{C}$ are given in Figure 2. Antistaphylococcal effect of essential oil and lactic acid alone was smaller in meat in comparison to their addition in meat broth. No significant difference ( $\mathrm{p}>0.05)$ was found for the microbial counts in meat treated with each antimicrobial alone or in mixture.

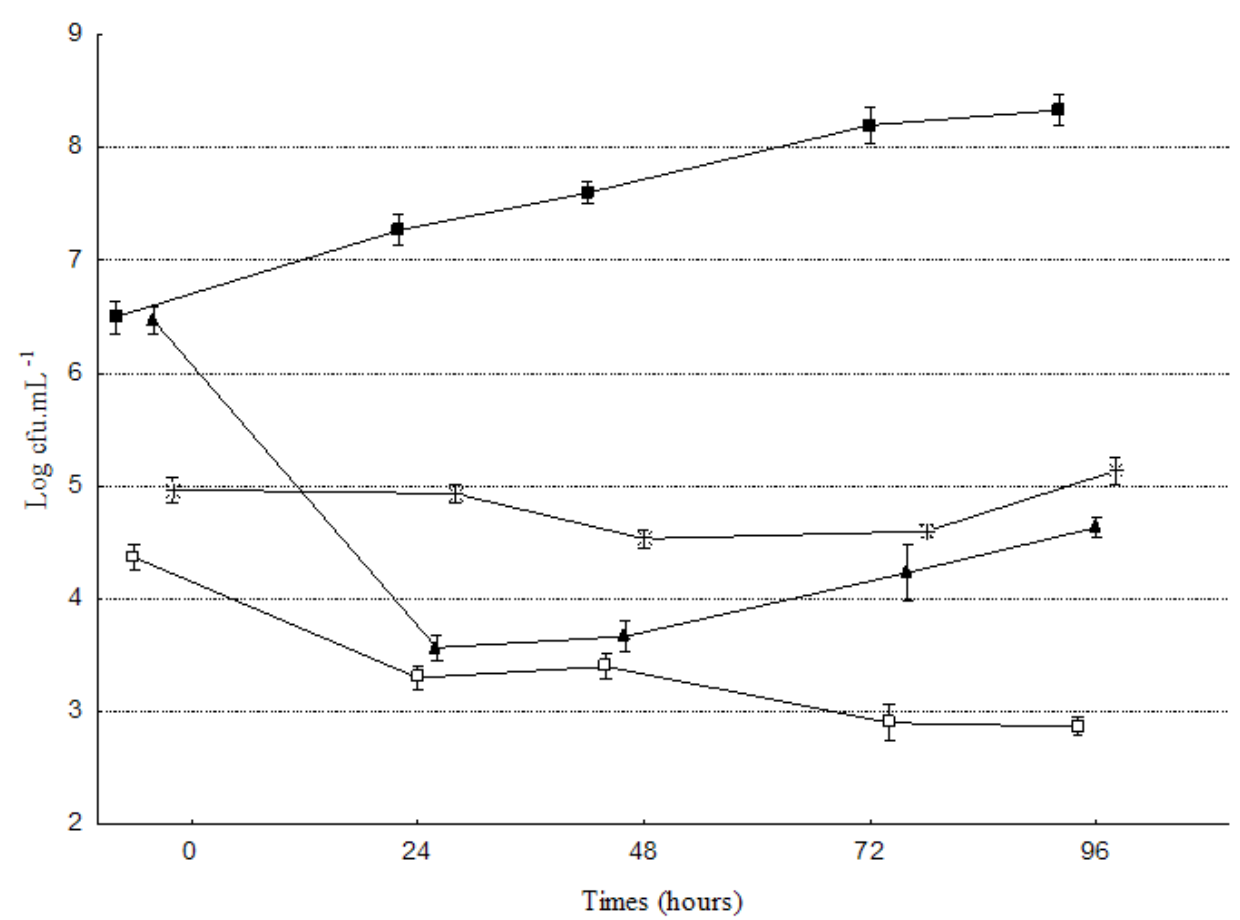

Figure 1. Viable cell counts of $S$. aureus QCE in meat broth at $7{ }^{\circ} \mathrm{C}\left( \pm 1^{\circ} \mathrm{C}\right)$ as a function of antimicrobial concentration: ( $\left.\mathbf{m}\right)$ : control (0 $\left.\mu \mathrm{L} \cdot \mathrm{mL}^{-1}\right)$; (०): essential oil (MIC: $\left.0.6 \mu \mathrm{L} \cdot \mathrm{mL}^{-1}\right)$; ( $\left.\mathbf{\Delta}\right)$ : lactic acid $\left(2.5 \mu \mathrm{L} \cdot \mathrm{mL}^{-1}\right.$; (+): essential oil $\left(\mathrm{MIC} \times 1 / 4: 0.15 \mu \mathrm{L} \cdot \mathrm{mL}^{-1}\right)+$ lactic acid $\left(\mathrm{MIC} \times 1 / 4: 0.62 \mu \mathrm{L} \cdot \mathrm{mL}^{-1}\right)$. 


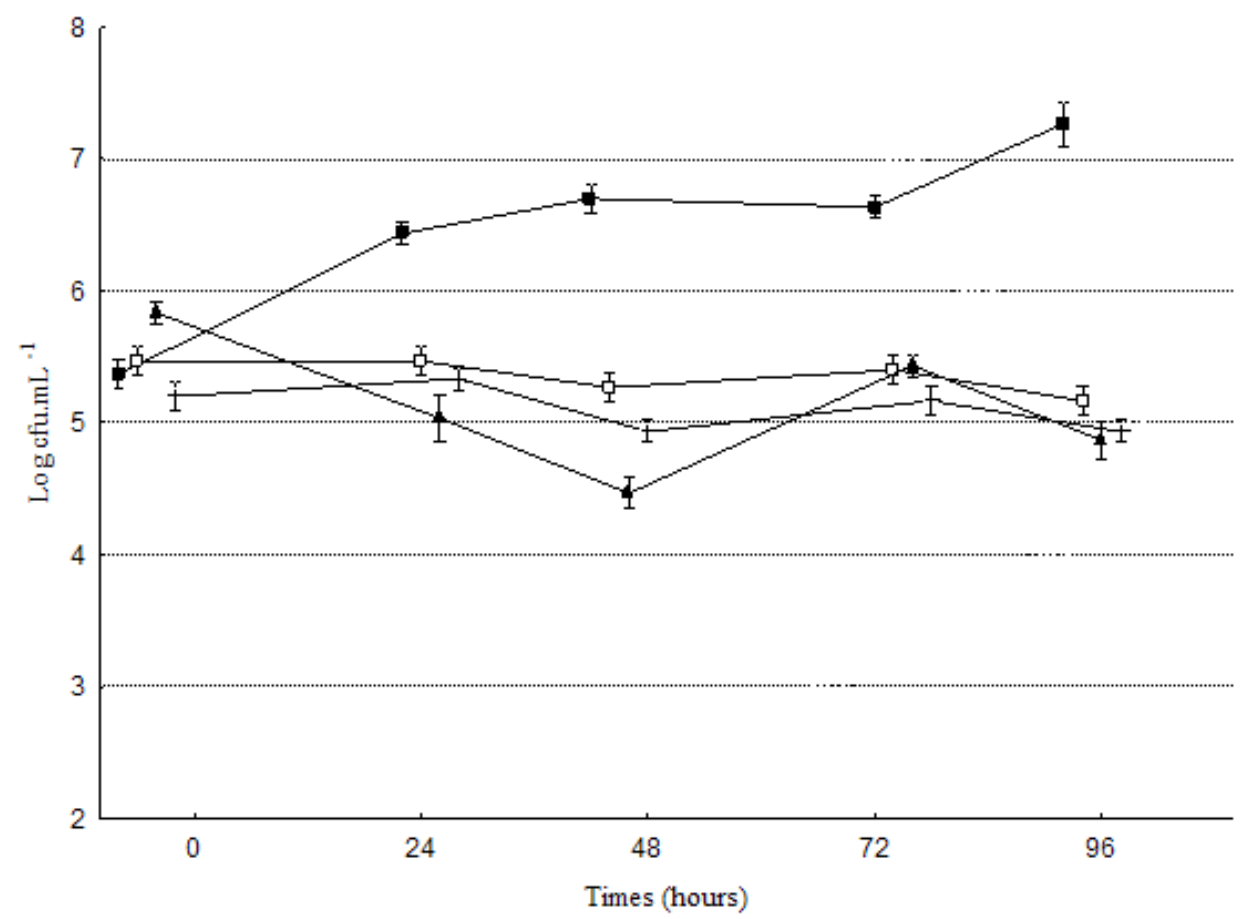

Figure 2. Viable cell counts of $S$. aureus QCE in meat model at $7^{\circ} \mathrm{C}\left( \pm 1^{\circ} \mathrm{C}\right)$ as a function of antimicrobial concentration: $(\mathbf{\square})$ :

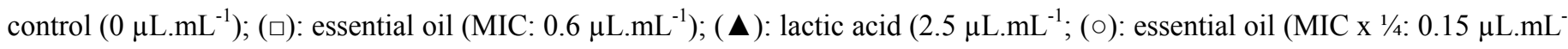
$\left.{ }^{1}\right)+$ lactic acid (MIC x 1/4:0.62 $\mu \mathrm{L} \cdot \mathrm{mL}^{-1}$ ).

O. vulgare essential oil and lactic acid showed a stronger kill-effect in meat broth in comparison to the food model (meat pieces). Lower antimicrobial effect of phenolics-compoundcontaining essential oils, when applied in food models has been attributed to their solubility in the aqueous phase of the foods and distribution in the substrate. Carvacrol, majority compound of the essential oil studied here, is much more soluble in the other constituents of foods than in aqueous phase, where the bacterial proliferation takes place. Moreover, the physical structure of a food may limit the antibacterial activity of an essential oil (6).

It has generally been found that a greater concentration of essential oils is needed to achieve the same antibacterial effect in foods $(24,28)$. Not only are the intrinsic properties of food (fat/protein/water content, antioxidants, $\mathrm{pH}$, salt and other additives) relevant in this respect, the extrinsic determinants (temperature, packaging in vacuum/gas/air, characteristics of microorganisms) can also influence bacterial sensitivity (21).

Since higher concentrations of essential oils are generally required when added to food, the application of essential oils in food may be limited due to changes in organoleptic and textural quality $(9,12)$. A challenge for practical application of essential oils in food is to develop optimized low dose combinations to maintain product safety and shelf-life, thereby minimizing the undesirable flavor and sensory changes associated with the addition of high concentrations of essential oils (15).

Dimitriević et al. (10) noted that the antilisterial effect of Thymus vulgaris and Rosmarinus officinalis essential oil (50, 100, 200 and $300 \mu \mathrm{L} . \mathrm{mL}^{-1}$ ) was noticeably increased by lactic acid $\left(50 \mu \mathrm{L} \cdot \mathrm{mL}^{-1}\right)$. On the other hand, the same study reported a smaller enhancing effect to $O$. vulgare essential oil. Naveena et al. (20) found that the combination of Syzygium aromaticum essential oil and lactic acid provided a decrease of 
psychrotrophic and coliform counts in buffalo meat.

According to Dimitriević et al. (10) it is difficult to understand what the way of establishment of the enhancing antimicrobial effect from the combined application of essential oils and organic acids. Studies on the antibacterial mechanism of phenolic compounds found in essential oils focused on their effects on the cellular membrane, changing its structure and permeability (26). Lin et al. (19) state that the damage to cell membrane might explain the observed effects, since phenolics could cause sublethal injury to cell membranes, causing disruption of proton motive force due loss of $\mathrm{H}^{+}$-ATPase. This could make bacteria more susceptible to acid environment. Moreover, at low $\mathrm{pH}$ the hidrophobicity of an essential oil increases, enabling it to more easily dissolve in the lipids of the cell membrane of target bacteria (17).

The results presented in this study showed a synergic effect of $O$. vulgare essential oil and lactic acid on the base of FIC index. Our results encourage further researches focusing the application of $O$. vulgare essential oil in low doses and other preservative hurdles, in order to control the growth of $S$. aureus in selected foods, particularly meat products. Such a strategy could be used by food industry as natural barrier to control the growth of $S$. aureus in foods providing the balance between sensory acceptability and antimicrobial efficacy.

\section{ACKNOWLEDGEMENTS}

The authors are grateful to Conselho Nacional de Desenvolvimento Científico e Tecnológico - CNPq (Brazil) for the financial support.

\section{REFERENCES}

1. AOAC International. (1995). Official Methods of Analysis, 16th ed., sec. 975.55. AOAC INTERNATIONAL, Arlington, VA.

2. Barros, J.C.; da Conceição, M.L; Gomes Neto, N.J.; da Costa, A.C.V.; Siqueira Júnior. J.P.; Basílio Júnior, I.D.; Souza, E.L. (2009). Interference of Origanum vulgare L. essential oil on the growth and some physiological characteristics of Staphylococcus aureus strains isolated from foods. Lebensm. Wiss. u.-Technol., 42: 1139-1143.

3. Baydar, H.; Sagdiç, O.; Ozkan, G.; Karadogan, T. (2004). Antibacterial activity and composition of essential oils from Origanum, Thymbra and Sartureja species with commercial importance in Turkey. Food Cont., 15: 169-172.

4. Bennet, R.W.; Yeterian, M.; Smith, W.; Coles, C.M.; Sassaman, M.; McClure, F.D. (1986). Staphylococcus aureus identification characteristics and enterotoxigenicity. J. Food Sci., 51: 1337-1339.

5. Bennis, S.; Chami, F.; Chami, N.; Bouchikhi, T.; Remma, A. (2004). Surface alteration of Saccharomyces cerevisae induced by thymol and eugenol. Let. Appl. Microbiol., 38: 454-458.

6. Burt, S. (2004). Essential oils: their antibacterial properties and potential applications in foods - a review. Int. J. Food Microbiol., 94: 223-253.

7. Canillac, N.; Mourey, A. (2001). Antimicrobial activity of the essential oil of Picea excelsa on Listeria, Staphylococcus aureus and coliform bacteria. Food Microbiol., 18: 261-268.

8. de Boer, E.; Zwartkruis-Nahuis, J.T.M.; Wit, B.; Huijsdens, X.W.; de Neeling, A.J.; Bosch, T.; van Oosteron, R.A.A.; Vila, A.; Heuvelink, A.E. (2009). Prevalence of methicillinresistant Staphylococcus aureus in meat. Int. J. Food Microbiol., 134: 52-56.

9. Devlieghere, F.; Vermeiren, L.; Debevere, J. (2004). New preservation technologies: possibilities and limitations. Int. Dairy Prod., 14: 273-285.

10. Dimitriević, S.I.; Mihajlovski, K.R.; Antonović, D.G.; MilanovićStevanović, M.R.; Mijin, D.Z. (2007). A study of the synergistic antilisterial effects of a sub-lethal dose of lactic-acid and essential oils from Thymus vulgaris L., Rosmarinus officinalis L. and Origanum vulgare L. Food Chem., 74: 774-782.

11. Dorman, H.J.D.; Deans, S.G. (2000). Antimicrobial agents from plants: antibacterial activity of plant volatile oils. Journal of Applied Bacteriology, 88, 308-316.

12. Fu, Y.J.; Zu, Y.G.; Chen, L.Y.; Shi, X.G.; Wang, Z.; Sum, S.; Efferth, T. (2007). Antimicrobial activity of clove and rosemary essential alone and in combination. Phytother. Res., 21: 989-994.

13. Gonçalves, A.C.; Almeida, R.C.C.; Alves, M.A.O.; Almeida, P.F. (2005). Quantitative investigation on the effects of chemical treatments in reducing Listeria monocytogenes population on chicken breast meat. Food Cont., 16: 617-622.

14. Gould, I.M.; Wilson, D.; Milne, K.; Peterson, A.; Golder, D.; Russel, D. (1991). Interaction of iminepen with erythromycin and tetracycline assessed by microdilution checkboard techniques. Antimicrob. Agent Chemother., 35: 2407-2409.

15. Gutierrez, J.; Barry-Ryan, C.; Bourke, P. (2008). The antimicrobial efficacy of plant essential oil combinations and interactions with food ingredients. Int. J. Food Microbiol., 124: 91-97.

16. Gutierrez, J.; Barry-Ryan, C.; Bourke, P. (2009). Antimicrobial activity of plant essential oils using food model media: efficacy, synergistic potential and interactions with food components. Food Microbiol., 26: 
142-150.

17. Juven, B.J.; Kanner, J.; Schved, F.; Weisslowicz, H. (1994). Factors that interact with the antimicrobial action of thyme essential oil and its active constituents. J. Appl. Bacteriol., 76: 623-631.

18. Leuschner, R.G.K.; Zamparini, J. (2002). Effects of spices on growth and survival of Escherichia coli 0157 and Salmonella enterica serovar enteridis in broth model systems and mayonnaise. Food Cont., 13: 399404.

19. Lin, Y.T.; Labbe, R.G.; Shetty, K. (2004). Inibition of Listeria monocytogenes in fish and meat system by use of oregano and cramberry phytochemical synergies. Appl. Environ. Microbiol., 70: 5672-5678.

20. Naveena, B.M.; Muthukumar, M.; Sen, A.R.; Babji, Y.; Murthy, T.R.K. (2006). Improvement of shelf-life of buffalo meat using lactic acid, cove oil and vitamin C during retail display. Meat Sci., 74: 409-415.

21. Nazer, A.I.; Kobilinsky, A.; Tholozan, J.-L.; Dubois-Brissonnet, F. (2005). Combination of food antimicrobials at low levels to inhibit the growth of Salmonella sv, Typhimurium: a synergistic effect. Food Microbiol., 22: 391-39.

22. Nostro, A.; Blanco, A.R.; Canntelli, M.A.; Enea, V.; Flamini, G.; Morelli, I.; Roccaro, A.S.; Alonzo, V. (2004). Susceptibility of methicillin-resistant staphylococci to oregano essential oil, carvacrol and thymol. FEMS Microbiol. Let., 230: 191-195.

23. Oliveira, C.E.V.; Stamford, T.L.M.; Gomes Neto, N.J.; Souza, E.L. (2010). Inhibition of Staphylococcus aureus in broth and meat broth using synergies of phenolics and organic acids. Int. J. Food Microbiol., 137: 312-316.

24. Pol, L.E.; Mastwijk, H.C.; Slump, R.A.; Popa, M.E.; Smid, E.J. (2001). Influence of food matrix on inactivation of Bacillus cereus by combinations of nisin, pulsed electric fields treatment and carvacrol. $J$. Food Prot., 64: 1012-1018.
25. Pesavento, G.; Ducci, B.; Comodo, N.; Nostro, A.L. (2007) Antimicrobial resistance profile of Staphylococcus aureus isolated from raw meat: a research for methicilin resistant Staphylococcus aureus (MRSA). Food Cont., 18: 196-200.

26. Shetty, K.; Wahlqvist, M.L. (2004). A model for the role of prolinelinked pentose phosphate pathway in phenolic phytochemicals biosynthesis and mechanism of action from human health and environmental applications. Asia Pacific Journal of Clinical Nutrition, 13: $1-24$.

27. Skandamis, P.; Tsigarida, E.; Nichas, G.J.E. (2002). The effect of oregano essential oil on survival/death of Salmonella typhimurium in meat stored at $5^{\circ} \mathrm{C}$ under aerobic, VP/MAP conditions. Food Microbiol., 19: 97-108.

28. Smith-Palmer, A.; Stewart, J.; Fyfe, L. (1998). Antimicrobial properties of plant essential oils and essences against five important food-borne pathogens. Let. Food Microbiol., 26: 118-122, 1998.

29. Souza E.L.; Stamford, T.L.M.; Lima E.O.; Trajano, V.N. (2007). Effectiveness of Origanum vulgare L. essential oil to inhibit the growth of food spoiling yeasts. Food Cont., 18: 409-413.

30. Souza, E.L.; Stamford, T.L., Lima, E.O. (2006). Sensitivity of spoiling and pathogen-food related bacteria to Origanum vulgare L. (Lamiaceae) essential oil. Braz. J. Microbiol., 37: 527-532.

31. Tsigarida, E.; Skandamis, P.; Nichas, G.J.E. (2000). Behavior of Listeria monocytogenes and authocthonous flora on meat stored under aerobic, vacuum and modified atmosphere packaging conditions with or without the presence of essential oil at $5^{\circ}$ C. J. Appl. Microbiol., 89: 901-909.

32. Vanderzant, C.; Splittstoesser, D.F. (1992). Compendium of methods for the microbiological examination of foods. $3^{\mathrm{a}}$ ed. Washington: American Public Health Association (APHA). 